\title{
Research on the Sharing of Urban and Rural High Quality Educational Resources under the Background of Big Data and Smart Education
}

\author{
Yu-jiao WANG ${ }^{1}$, Hai-yun $\mathrm{LIN}^{1,{ }^{*}}$ and Jun-wei WANG ${ }^{2}$ \\ ${ }^{1}$ Department of Physical Science and Technology, Kunming University, Yunnan, Kunming, China \\ ${ }^{2}$ Kunming radio and television network limited liability company, Yunnan, Kunming, China \\ ${ }^{*}$ Corresponding Author
}

Keywords: Big data, Smart education, High-quality education resources in urban and rural areas, Sharing model.

\begin{abstract}
Big data and smart education have brought new opportunities for the ecological construction of high quality education resources. Combined with the present situation of the sharing of high quality education resources in urban and rural areas, this paper analyzes the promotion of the big data and smart education to the sharing of high quality education resources in urban and rural areas from three levels: big data, wisdom education and smart education resource platform based on big data. A set of intelligent education resource sharing mode based on big data environment is established, and a new thought for the sharing of quality education resources between urban and rural areas is provided.
\end{abstract}

\section{Introduction}

With the globalization of education informatization, artificial intelligence, data mining, cloud computing, big data, such as information technology constantly emerging, wisdom city, education wisdom, wisdom health care, intelligent transportation put forward the concept of "wisdom", education sector set off a wave of "wisdom" [1]. Wisdom learning as the core of the smart education and the fundamental cornerstone has entered the people's vision. Big data that is introduced into education field as a kind of new technology and new means of subverts the traditional teaching mode, promote the use of big data in the field of education, is the realistic demand and the future trend of education development in our country[2]. How to effectively use mass smart education resources, strengthen the deep fusion of big data and education, to overcome the learning barriers, to achieve wisdom study, is a focus of many scholars attention. at the same time ,to promote the development of education informationization, to promote scientific education policy, the urban and rural education resources allocation rationalization and provides a new opportunity for the education balanced development.

\section{The Development Path of Big Data and Smart Education}

Held in Beijing in January 2016, the theme of "big data driven education reform" of the national conference, also YanJianHui, director of the national statistical information service at the meeting pointed out that "education is about the national economy and people's livelihood, education and complicated problem, big data in reshaping education has unlimited potential[3]. In the current situation, education should be defined as big data from strategic point of view to promote the innovation of the education reform of strategic assets, promote the development of the scientific concept of the comprehensive reform of education field and the foundation of smart education.[4]" In September 2015, promulgated by the state council in action outline for promoting the development of big data clearly put forward to improve the education of public service platform, promote the construction of education culture big data, give full play to the big data technology support for education reform, to illustrate that the application of big data in the field of education has been risen to national strategy level[5]. In April of 2016, China's first big education development report data - the data development blue book of Chinese basic education, in the blue 
book on education big data basic theory, development idea and application paradigm, the development of education big data determines the future of education, is the evolution of deepening the reform of education field and promote education innovation. In January 2017, the national education career "much starker choices-and graver consequences-in planning (hereinafter referred to as the" planning ") pointed out that "encourage schools to use big data technology to carry out the education teaching activities and students behavior data collection, analysis and feedback, provide support to promote the individualized learning and teaching" "the comprehensive utilization of the Internet, big data, artificial intelligence and virtual reality technology to explore the future education teaching new mode".

\section{Domestic and International Development Dynamic Analysis}

Through the analysis of domestic and foreign research status, it has been found that the smart education has become the new direction of international education information development. China's development smart education has a strong realistic demand, and relevant researches have made preliminary progress. Although all cities in China have begun to build the smart education system service platform in the big data environment, there are still many common problems in the construction process. System developers and education workers lack deep communication, resulting in low efficiency of the system[6]. And because the regional economy, history and culture, education level, network communication, information technology, such as constraints, most smart education resources platform for the construction of the lack of global planning and extension of train of thought. The service facilities and operation modes are also different, and it is difficult to achieve the resource interconnection between the smart education platform. Although governments and education departments at all levels constantly increase investment in rural education informatization construction, around the high-quality teaching resources sharing and application in parts of rural school has achieved a certain effect, rural school informatization infrastructure also had the very big enhancement, but the pace of urban and rural education development and education level still exists obvious difference, quality problems still exist in the process of the sharing of teaching resources.

\section{Big Data Boost the Balanced Development of Urban and Rural Education}

Big data drive the scientific education policy and the education resources rationalization process, at the same time, the big data also helps to find and narrow regional differences in the quality of education opportunities, education, effectively promote the balanced development of the regional education, embodied in the following respects.

\section{Timely Adjust Education Policy}

Subject to the access to data and analysis technology of traditional education, the reflection of the education condition is limited, one-sided, the trend of future development of regional education and policy is not supported effectively [7]. By the use of big data technology, we can achieve diversification of huge amounts of data acquisition, processing and analysis. The paper summarizes the relationship between the multiple data, build a development model, further analysis of various elements in the regional education development, reveals the main factors influencing the equilibrium development of education, for the adjustment of the education policy to provide accurate scientific basis.

\section{Scientific Allocation of Education Resources}

Traditional education data that reflect the situation of education is more general and vague, which makes it difficult to provide accurate guidance for education organization layout and education funding adjustment decision. Education data recorded under the support of big data technology reflects immediacy, process behavior and phenomenon, more detailed and detailed; collects comprehensive area within the scope of the distribution of education institutions and education 
funds input data, etc., combining with the regional economic development, population structure, such as information, to establish a scientific evaluation model, adjust the distribution of education institutions, education funds allocation strategy, realize the rational allocation of education resources.

\section{Promote Equal Opportunities for Education}

Traditional education data has one-sidedness and delayed defects, and increasingly perfect and refined big data, according to the data produced in the system at the same time from the macro and micro level, reflect the education opportunity fair degree of area [8]. Through the collection and correlation of students' information in the region, the balanced development trend of education in the region can be predicted, and the resources and capital allocation and teaching environment can be adjusted accordingly.

\section{The Smart Education Resource Platform based on Big Data Promotes High-Quality Education Resource Sharing in Urban and Rural Areas}

\section{Improve Education Resource Utilization Efficiency}

Based on the wisdom of big data, education resource platform can effectively avoid the duplication of input of manpower and material resources and reduce the waste of education resources [9]. Resource platform, meanwhile, will also promote the education management mode change, because education managers can be based on a resource platform, provides information and information, minimize repeated study, invalid, can put more time and energy into the study of professional level higher, thus reducing the research and development and operating costs. For schools, on the other hand, large scientific instrument, lab can through the platform to realize sharing resources, such as this will reduce the operating difficulties from technology equipment purchase and financial pressure. Therefore, the smart education resource platform based on big data can realize the economy of national science and technology investment and improve the utilization efficiency of education big data through resource opening and sharing.

\section{Reduce Education Resource Loss}

In the past, the standardization and continuity of education data accumulation and maintenance were poor and basically in the state of relaxation, which could easily lead to the loss of education data, thus resulting in immeasurable losses. After the establishment of smart education resources platform based on big data, will be many education big data collection together, form a valuable resource, unified storage, management and maintenance, therefore, smart education resources platform based on big data has education resources accumulation and maintenance capabilities, helps to prevent loss of education resources.

\section{Promote Education Big Data Resource Sharing}

Education resource platform based on big data is both a platform and a carrier, which can provide universal public services for education and scientific and technological innovation activities in the whole society. At the same time, the resource platform can effectively solve the information asymmetry in education activities, the difficulty of resource docking and the unfair distribution of resources. Resource sharing of large-scale scientific research instruments, venues and laboratories can be realized through resource platform, thus improving the utilization rate of site equipment and reducing the waste of education resources.

\section{Strengthen Education Communication and Cooperation}

Education resource platform based on big data can not only improve education resource information storage capacity, but also promote education communication and cooperation. The platform USES the most advanced network, digital and multimedia information technology, build sharing service platform, the latest and technical innovation achievements of education teaching timely display and transmission. Students, teachers, management and other personnel can learn cutting-edge 
information, share education big data knowledge, master the latest development and realize education communication and cooperation in a timely manner through the platform.

\section{Play Education Resource Potential Value}

Education big data is of great use value as an important resource type. The establishment of education resource platform based on big data will contribute to the full play of scientific value, social value and economic value contained in education data. In addition, relying on the resources to promote resources sharing platform, to strengthen the cooperative innovation, can produce new scientific research achievements, and the new research achievements and formed a new resources, and from this point, value-added effect is made by the use of educational big data resources sharing.

\section{Smart Education Boosts the Sharing of High-Quality Education Resources in Urban and Rural Areas}

The goal of smart education is to make the performance of education more efficient based on the new generation of information technology. smart education is modern education integration rapid development of information technology, in education, education management, education teaching resources to maximize the integration and sharing, use as the core, thereby established a certain range (area, city, country) in every stage of education, basic education, vocational education, higher education, etc.) of the intelligent system of education. Many countries (including the developed countries) have developed the development smart education as a major strategic target for education development. The construction of education has become the new direction of the global education informatization. Educators use smart education to cultivate learners of flexible thinking ability and the ability to find and solve problems, promote the development of the learners personalized and diversified wisdom, the wisdom of the construction of perfect education resources platform, and provide a diversified and intelligent education teaching environment, cultivate smart talent contribute to the development of socialism with Chinese characteristics.

In the context of accelerating the construction of the "three links and two platforms" in the whole country, the smart education resource platform in the big data environment is built around the requirements of the development of national education informatization, and the personalized platform of "three links and two platforms" is realized. smart education resources platform using big data and cloud computing technology as running security, make the education informatization infrastructure construction, the high quality digital education resources sharing, information technology and the depth of the education teaching fusion, education of information science development mechanism, the balanced development of the urban and rural education has achieved new breakthroughs, and create a conducive to learners wisdom, personalized, diversified and lifelong education to the growth of the new environment, the formation of "classroom use, often use, common use" under the informatization of education teaching new normal.

\section{Conclusion}

Under the background of big data and wisdom education, the balanced development of urban and rural education should be based on data and accurately grasp the development of urban and rural education. Educators need new ways of thinking, new methods and new educational models to break through bottlenecks and solve problems, and to strengthen the deep fusion of the new generation of information technology ideas and education. The smart educational resource platform based on the big data provides users with real-time, accurate, flexible and open shared services, which greatly improves the quality of educational resources sharing services, and provides an effective solution for the imbalance of urban and rural quality education resources, poor scalability, and resource duplication. 


\section{Acknowledgement}

This is the research result of Yunnan Planned Project for Philosophy, Social Sciences and Educational Science entitled "A Study of the Effective Approaches to Share Urban Excellent Educational Resources with the Rural Areas in the Context of 'Internet Plus Education"' (Project number: AC17018).

\section{References}

[1] Yong-qian LIU, Xian-ming Yang. New ideas for the balanced development of education in the era of big data [J], E-Education Research, 5(2014) 11-14.

[2] Ya-xin Liu, Chao-chao Xu, Linli-Wang, Xian-ming Yang. The digital education resource ecological construction supported by big data[J],Modern Educational Technology, 10(2016) 5-11.

[3] Zhi-ting ZHU, Yan-yan SUN, Hong-chao PENG. Understanding Cultural Implications of Big Data in Education[J],E-Education Research,1(2017) 28-36.

[4] Shao-li Zhang, Zheng Xiao-qi, Hui Zhang. Research on the construction and mechanism of education big data information platform based on resource sharing[J], Journal of Modern Information,12(2017) 90-95.

[5] Xue-mei YANG, Ting CAI. Research on the co-construction and sharing of information resources of university of applied technology in cloud computing and big data environment[J]. Education modernization. 11(2017) 183-186.

[6] Fu-shuai REN, Research and application of regional wisdom education cloud platform based on Hadoop[D], JILIN University,2016.

[7] Yan-nan ZHANG.A study of big data applications in the field of education based on the practice in America[D], East China Normal University, 2016.

[8] Zhi-ting ZHU. With smart education led education information innovation development [J], The Chinese Journal of ICT in Education. 9 (2014) 4-8.

[9] Zhi-ting ZHU.Take the smart education to lead the reform and innovation of informatization education [J]. Invention and Innonation. 1(2014) 4-8. 